\title{
AN APPLICATION OF EFFECTIVE GENETIC ALGORITHMS FOR SOLVING HYBRID FLOW SHOP SCHEDULING PROBLEMS
}

\author{
CENGIZ KAHRAMAN* \\ Department of Industrial Engineering, İstanbul Technical University, Maçka, Ístanbul, Turkey. \\ ORHAN ENGIN \\ Department of Industrial Engineering, Selçuk University, Konya, Turkey. \\ İHSAN KAYA \\ Department of Industrial Engineering, İstanbul Technical University, Maçka, İstanbul, Turkey. \\ MUSTAFA KERIM YILMAZ \\ Department of Industrial Engineering, Selçuk University, Konya, Turkey. \\ Received:04-09-2007 Revised:04-12-2007
}

\begin{abstract}
This paper addresses the Hybrid Flow Shop (HFS) scheduling problems to minimize the makespan value. In recent years, much attention is given to heuristic and search techniques. Genetic algorithms (GAs) are also known as efficient heuristic and search techniques. This paper proposes an efficient genetic algorithm for hybrid flow shop scheduling problems. The proposed algorithm is tested by Carlier and Neron's (2000) benchmark problem from the literature. The computational results indicate that the proposed efficient genetic algorithm approach is effective in terms of reduced total completion time or makespan $\left(\mathrm{C}_{\max }\right)$ for HFS problems.
\end{abstract}

Key words: Hybrid flow shop scheduling, Genetic algorithm, completion time

\section{Introduction}

A HFS scheduling problem consists of series of production stages, each of which has several machines operating in parallel. Some stages may have only one machine, but at least one stage must have multiple machines. Each job is processed by one machine in each stage and it must go through one or more stages. Machines in each stage can be identical, uniform or unrelated (Linn and Zhang, 1999). The hybrid flow shop scheduling problems can be formally described as follows (Engin and Döyen 2004): Machines are arranged into $s$ stages in series; in each stage $k(k=1, \ldots, s)$ there are $m_{k}$ identical machines in parallel; job $j, j=1, \ldots, n$, has to be processed on any machine at each stage and job $j$ has finite processing times in each stage $\left(p_{l j}\right.$, $\left.p_{2 j}, \ldots, p_{s j}\right)$. We assume that all jobs and machines are always available during the scheduled period and the preemption is not allowed. The objective is to find a schedule which minimizes the maximum completion time (makespan). HFS problems are NP-Hard when the objective is to minimize the makespan (Gupta, 1988).

A hybrid flow shop scheduling problem's mathematical model is described as a mix integer programming. The model is given as follows (Hong Wang 1998):

The notation of the HFS model;

$J$ : The set of the jobs to be scheduled, $|J|=n$,

$s:$ The set of the stages that all the jobs will be processed, $|s|=s$,

$j$ : Subscript representing job $j$

$l$ : Subscript representing stage $l$,

" Corresponding Author:

E-Mail: kahramanc@itu.edu.tr

Phone: +90-212-29640 40

Fax:+90-212-240 7260 
$i$ : Subscript representing machine $i$,

$m_{l}$ : The number of the machines at stage $l$,

$B$ : a very large positive number,

$S_{j l}$ : Starting time of job $j$ at stage $l$,

$\forall j, j \in J, \forall l, l \in S$,

$X_{j l i}=\left\{\begin{array}{cr}1, & \text { if } j o b j \text { is on machine } i \text { at stage } l . \\ 0, & \text { otherwise }\end{array} ;\right.$

$\forall j, j \in J, \forall l, l \in s, i=1, \ldots \ldots, m_{l}$

$Y_{f g l i}=\left\{\begin{array}{c}1, \text { if job } f \text { is before job } g \text { on machine } i \text { at stagel } \\ 0,\end{array}\right.$

$\forall j, j \in J, \forall l, l \in s, i=1, \ldots \ldots, m_{l}$

$p_{l j}$ : Processing time of job $j$ at stage 1 ;

$\forall j, j \in J, \forall l, l \in S$,

Minimize Q

Subject to

$S_{j s}+p_{j s} \leq Q ; \forall j$

$S_{j l}+p_{j l} \leq S_{j, l+1} ; \forall j, l, l \neq S$

$S_{f l}+p_{f l} \leq S_{g l}+B\left(1-Y_{f g l i}\right) ;$

$\forall l, i, f, g, f \neq g$

$Y_{f g l i}+Y_{g f l i} \leq 1 ; \forall l, i, f, g, f \neq g$

$X_{f l i}+X_{g l i} \leq 1+Y_{f g l i}+Y_{g f l i}$;

$\forall l, i, f, g, f \neq g$

$\sum_{i=1}^{m_{l}} X_{j l i}=1 \quad \forall j, l$

$S_{j l} \geq 0 ; \quad \forall j, l$

$X_{j l i}, Y_{f g l i} \in\{0,1\}$

Constraint (2.1) indicates that the completion time of the last job at the last stage $s$ is $Q$.
Constraint (2.2) indicates that it is not possible for job $j$ to be processed at stage $l+1$ before job $j$ at stage $l$ is completed. The processing order for jobs $f$ and $g$ on machine $i$ at stage $l$ is defined by constraints (2.3), (2.4), and (2.5). These constraints do not allow more than one job to be processed on a machine at any time. Constraint (2.6) does not allow a job to be processed on more than one machine at any time. Constraints (2.7) and (2.8) provide that the variables are nonnegative and $0-1$ integer values.

A HFS problem with 5 -jobs $\times 3$-stages where the stages have 2, 3, and 3 machines respectively is given in Fig. 1. 


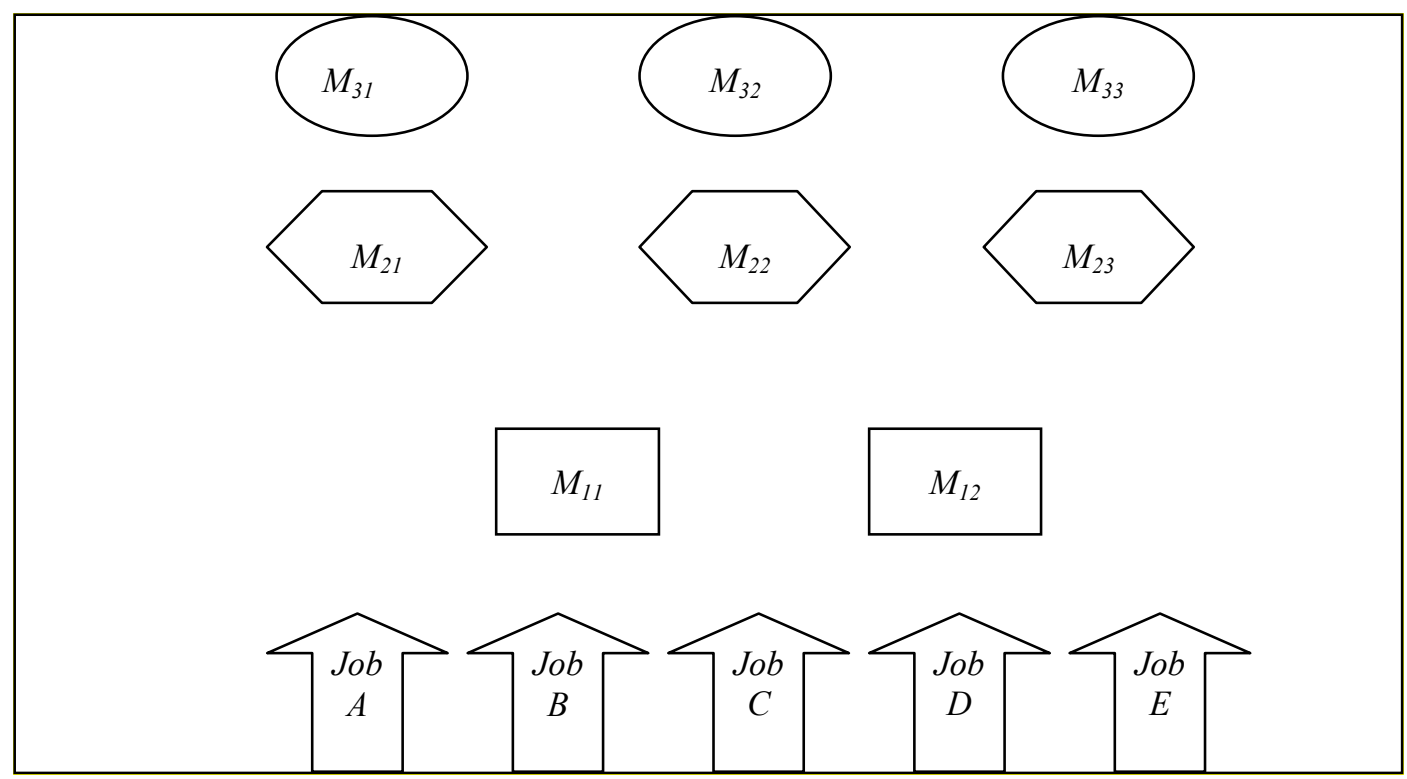

Figure 1. An Illustrative Hybrid Flow Shop Scheduling Problem

The HFS was first studied by Arthanari and Ramamurthy (1971). They developed a branch and bound algorithm for solving HFS problems. Gupta (1988) and Hoogeveen et al. (1996) proved that the two stage hybrid flow shop scheduling problem was
NP-Hard in the stronge sense even if there was only one machine on the first stage and two machines on the second stage. The other studies on the hybrid flow shop scheduling problems in the literature are given in Table 1.

Table 1. Literature review on HFS scheduling problems.

\begin{tabular}{|c|c|c|c|}
\hline The Authors & Year & Problem & Algorithm \\
\hline Brah and Hunsucker & 1991 & $\begin{array}{c}\text { Flow shop with multiple } \\
\text { processors }\end{array}$ & Branch and bound \\
\hline Portmann et al. & 1998 & HFS & Genetic Algorithm \\
\hline Riane et al. & 1998 & HFS & Heuristic methods \\
\hline Jessen and Weizhen & 1998 & HFS & On line algorithm \\
\hline Moursli and Pochet & 2000 & HFS & Branch and bound \\
\hline Soewandi and Elmaghraby & 2001 & Flexible flow shops & Heuristic method \\
\hline Neron et al. & 2001 & HFS & Branch and bound \\
\hline Engin and Döyen & 2004 & HFS & Artificial immune system \\
\hline Yang et al. & 2005 & Complex- HFS & Heuristic method \\
\hline Tang et al. & 2005 & Dynamic-HFS & Neural network \\
\hline Zhong et al. & 2006 & Multi-objective- HFS & Evolutionary algorithm \\
\hline Haouari et al. & 2006 & Two stage- HFS & Branch and bound \\
\hline Allaoui and Artiba & 2006 & Two stage- HFS & Branch and bound \\
\hline Zandieh et al. & 2006 & HFS & Immune algorithm \\
\hline Janiak et al. & 2007 & HFS & $\begin{array}{c}\text { Constructive and } \\
\text { metaheuristics algorithms }\end{array}$ \\
\hline Vob and Witt & 2007 & HFS & Heuristic solution \\
\hline Caricato et al. & 2007 & HFS & Heuristic method \\
\hline Alaykıran et al. & 2007 & HFS & Ant colony optimization \\
\hline
\end{tabular}


There are a few studies on hybrid flow shop scheduling problems solved by GAs.

Wang et al. (2006) proposed an effective hybrid genetic algorithm (HGA) for permutation flow shop scheduling with limited buffers. In the HGA, not only multiple genetic operators based on evolutionary mechanism are used simultaneously in hybrid sense, but also a neighborhood structure based on graph model is employed to enhance the local search, so that the exploration and exploitation abilities can be well balanced. They investigated the effects of buffer size and decision probability on optimization performances using simulation.

Oğuz and Ercan (2005) proposed a GA for hybrid flow-shop scheduling with multiprocessor task problems and described its implementation. They improved a new crossover operator to be used in the GAs and compared it with Partially Matched Crossover (PMX). They also employed a preliminary test to establish the best combination of the control parameters to be used along with different genetic operators.

Li-Xin et al. (2002) developed a genetic descent algorithm for hybrid flow shop scheduling problem. Randomly generated 230 instances were tested by simulation program. Computational experiments show that for small size HFSS scheduling problems, the average deviation of GDA from the optimal solution is $0.01 \%$; for medium-large size problems, the performance of GDA is $10.45 \%$ better than that of NEH algorithm.

Xia et al. (2000) proposed a GA approach for hybrid flow shop scheduling problem. The algorithm is based on the list scheduling principle by developing job sequences for the first stage and queuing the remaining stages in a FIFO manner.

In this paper, an effective GA is developed for HFS scheduling problems. The effectiveness of the proposed method is tested with Carlier and Neron's
(2000) HFS scheduling problems from the literature. The computational results indicate that the proposed approach is effective in terms of reduced makespan for the attempted problems. To the best of our knowledge, there are no genetic algorithms applied to Hybrid flow shop including Carlier and Neron's (2000) scheduling problems in the literature.

The rest of the paper is organized as follows. The proposed effective algorithm is explained in Section 2. In Section 3, an extensive computational study using the proposed algorithm and experiments are presented. In Section 4, the paper is concluded with some comments.

\section{Genetic Algorithms}

GAs were invented by John Holland (Goldberg, 1989) and they were stochastic search methods designed to search large and complex spaces by exploitation of currently known solutions and a robust exploration of the entire search space (Yoon and Ventura, 2002).

GAs use a collection of solutions called population. Each individual in the population is called a chromosome (a string of symbols) and a chromosome represents a solution to the problem. The chromosomes can be produced through successive iterations, called generations and the population size (the number of individuals in a population) remains fixed from generation to generation. The chromosomes are evaluated using the value of the fitness function during each generation. A set of genetic operators such as reproduction (selection) and recombination (crossover and mutation) is applied to create new and better solutions (off springs) from the individuals of the current population and the solutions are steadily improved from generation to generation. The structure of GAs is given in Fig. 2. 


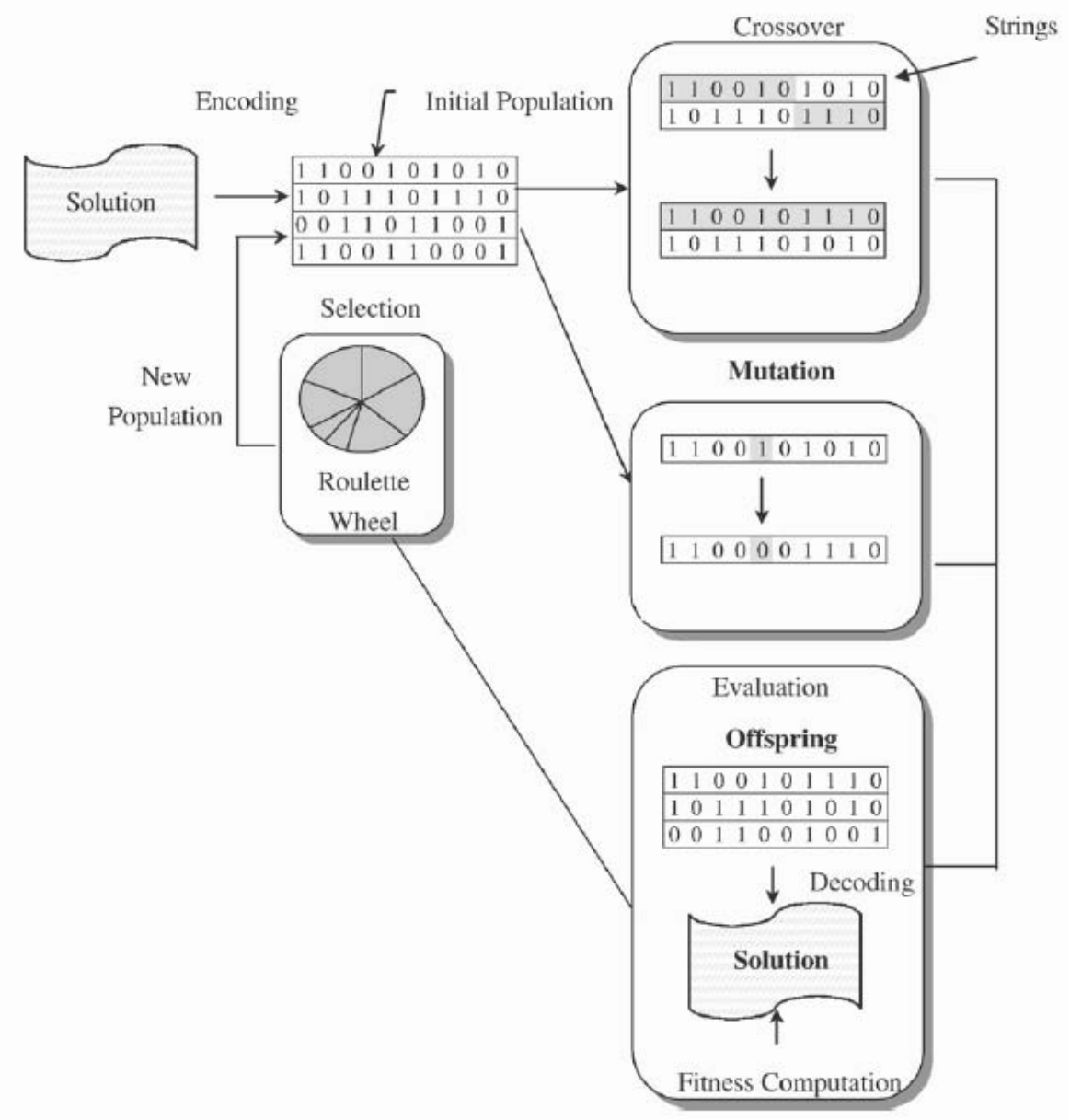

Figure 2. The fundamental cycle and operations of basic GAs (Gen and Cheng, 2000)

The proposed GA is based on a permutation representation of the $n$ jobs. The details of our implementation for the GAs are given as follows.

A direct coding approach is used. In this coding, a chromosome represents a schedule directly (Yamada et al., 1992). The initial population is randomly generated. The population size is determined by the help of a full factorial experimental design using our GA program.

Selection schemes allow the algorithm to take biased decisions favoring good strings when generations change. For this aim, some of the good strings are replicated while some of bad strings are removed. As a consequence, after the selection mechanism is determined, the population is likely to be "dominated" by good strings. Various selection schemes in the literature have been used. We focus on roulette wheel selection and tournament selection without replacement.

The fitness function plays an important role in deciding the string in the next generation. The fitness function of a string is defined by the makespan $\left(C_{\max }\right)$ value of the schedule.

Crossover is used as the main genetic operator and the performance of a GA is heavily dependent on it. During the past three decades, various crossover operators have been proposed for the scheduling problems. In this study, six crossover operators have been used: Position Based Crossover $(P B X)$, Order Crossover $(O X)$, Partially Mapped Crossover $(P M X)$, Cycle Crossover $(C X)$, Linear Order Crossover $(L O X)$ and Order Based Crossover $(O B X)$ that are widely used in the literature. These six crossover operators are briefly explained in the following:

\section{$P B X$}

First, it is generated a random mask and then exchanged relative genes between parents according to the mask. This operator is explained and detailed in section 3.1. 


\section{OX}

The offspring inherits the elements between the two crossover points from the selected parent in the same order and position as they appear in the parent. The remaining elements are inherited from the alternate parent in the order in which they appear in that parent, beginning with the first position following the second crossover point and skipping over all elements already present in the off spring (Kaya and Engin, 2007; Cheng et al. 1999).

\section{$P M X$}

A parent and two crossover sites are selected randomly and the elements between two string positions in one of the parents are directly inherited by the offspring. Each element between the two crossovers points in the alternate parent are mapped to the position held by this element in the first parent. Then the remaining elements are inherited from the alternate parent (Kaya and Engin, 2007; Cheng et al. 1999).

\section{CX}

The cycle between strings is fined, the symbols in the cycle are coped to a new string, the remaining symbols are determined for the new string by deleting the symbols and the remaining symbols are fulfilled with the new string.
LOX

The two sublists are selected from strings randomly. Sublist ${ }_{2}$ is removed from string ${ }_{1}$, leaving some "holes" and then holes are slide from the extremities toward the center until they reach the cross section. Similarly, Sublist ${ }_{1}$ is removed from string $_{2}$. At the end, Sublist $t_{1}$ is inserted into the holes of string ${ }_{2}$ to form offspring ${ }_{1}$ and sublist t $_{2}$ is inserted into the holes of string 1 to form offspring (Gen and $_{2}$ Cheng, 2000).

\section{$O B X$}

A set of positions is selected randomly; the order of symbols in the selected positions is imposed on the corresponding symbols in the other string.

Mutation operator plays a very important role in GAs and it helps maintain diversity in the population to prevent premature convergence. Six mutation operators are examined in the GA to minimize the makespan in HFS. These are neighborhood based, adjacent two job change, arbitrary two job change, arbitrary three job change, shift change and inversion mutation operator.

\section{Computational Results}

The proposed GA can be summarized as follows; 


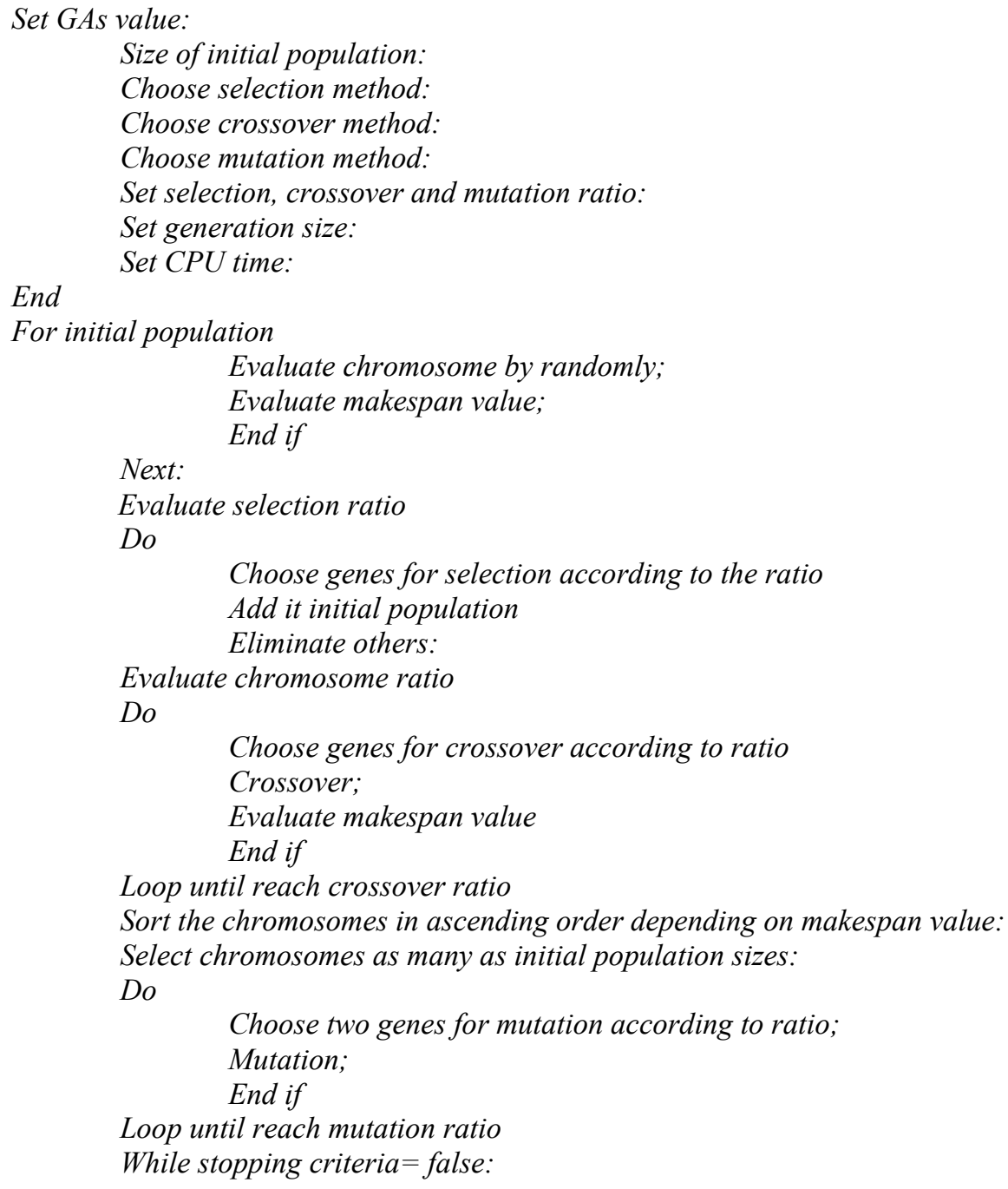

Next:

Evaluate selection ratio

Do

Choose genes for selection according to the ratio

Add it initial population

Eliminate others:

Evaluate chromosome ratio

Do

Choose genes for crossover according to ratio

Crossover;

Evaluate makespan value

End if

Loop until reach crossover ratio

Sort the chromosomes in ascending order depending on makespan value:

Select chromosomes as many as initial population sizes:

Do

Choose two genes for mutation according to ratio;

Mutation;

End if

Loop until reach mutation ratio

While stopping criteria $=$ false:

\subsection{Parameter optimization for GAs}

It is well known that GAs' efficiency depends on a high degree upon the selection of the control parameters. GAs' search process is controlled with multiple factors (control parameters) whose effects will possibly interact with each other. In general, there are a few control mechanisms for these parameters and in this paper the full factorial Design of Experiments (DOE) is used. The application involves six parameters (factors), each having possible different values. These parameters are given in Table 2 .

Table 2. The levels of GA control parameters

\begin{tabular}{ll}
\hline \multicolumn{1}{c}{ Control Parameters } & \multicolumn{1}{c}{ Levels } \\
\hline Selection methods & Roulette wheel, Tournament. \\
Selection ratios & $0.1,0.2,0.3,0.4,0.5,0.6,0.7,0.8,0.9,1.0$ \\
Crossover Methods & PBX, OX, PMX, CX, LOX, OBX \\
Crossover Ratios & $0.1,0.2,0.3,0.4,0.5,0.6,0.7,0.8,0.9,1.0$. \\
& Neighborhood based, adjacent two job change, arbitrary two job change, arbitrary three job \\
Mutation Methods & change, shift change, and inversion \\
Mutation Ratios & $0.1,0.2,0.3,0.4,0.5,0.6,0.7,0.8,0.9,1.0$ \\
\hline
\end{tabular}

The benchmark problems given in Carlier and Neron (2000) are considered in the study. The problem size varies from $10 \mathrm{job} \times 5$ stages to 15 job $\times 10$ stages. Processing times have a uniform distribution in the range of $(3,20)$. Three characteristics that define a problem are no. of jobs, no. of stages and no. of identical machines at each stage. Total 77 problems are classified into 13 
groups according to their characteristics. An instance problem is taken from each of the groups. Parameter optimization is implemented and the best parameter set is found for the instance. The parameter set found for an instance is generalized and used for the other problems in the same group. Therefore, parameter optimization is implemented for 13 instances. In the study, two selection methods, ten selection ratio levels, six crossover methods, ten crossover ratio levels, five mutation methods, and ten mutation ratio levels are implemented among the 13 problems. A total number of $2 \times 10 \times 6 \times 10 \times 6 \times 10=72000$ runs are made among these problems. The best parameters set in each of the replicated runs for 13 benchmark problems are given in Table 3. The initial population is selected as 25 for all benchmark problems.

Table 3. The best parameters sets of 13 benchmark problems

\begin{tabular}{ccccccc}
\hline Problem & $\begin{array}{c}\text { Selection } \\
\text { Method }\end{array}$ & $\begin{array}{c}\text { Selection } \\
\text { Ratio }\end{array}$ & $\begin{array}{c}\text { Crossover } \\
\text { Method }\end{array}$ & $\begin{array}{c}\text { Crossover } \\
\text { Ratio }\end{array}$ & $\begin{array}{c}\text { Mutation } \\
\text { Method }\end{array}$ & $\begin{array}{c}\text { Mutation } \\
\text { Ratio }\end{array}$ \\
\hline j10c5a2 & & 0.4 & & 0.3 & & 0.1 \\
j10c5b1 & & 0.4 & & 0.3 & & 0.1 \\
j10c5c1 & & 0.4 & & 0.3 & & 0.1 \\
j10c5d1 & & 0.4 & & 0.3 & & 0.1 \\
j10c10a1 & & 0.1 & & 0.2 & & 0.1 \\
j10c10b1 & Roulette & 0.1 & Position Based & 0.2 & Inversion & 0.1 \\
j10c10c1 & wheel & 0.1 & Crossover & 0.2 & mutation & 0.1 \\
j15c5a1 & & 0.1 & & 0.3 & & 0.2 \\
j15c5b1 & & 0.1 & & 0.3 & & 0.2 \\
j15c5c1 & & 0.1 & & 0.3 & & 0.2 \\
j15c5d1 & & 0.1 & & 0.3 & & 0.2 \\
j15c10a1 & 0.2 & & 0.1 & & 0.1 \\
j15c10b1 & 0.2 & & 0.1 & & 0.1 \\
\hline
\end{tabular}

The best selection, crossover and mutation methods for 13 benchmark problems are briefly described as follows:

\section{Roulette wheel selection}

Roulette wheel selection is chosen, where the average fitness of each chromosome is calculated depending on the total fitness of the whole population. The chromosomes are randomly selected proportional to their average fitness. Roulette wheel selection is summarized in the following steps,

Step1. Let the pop-size, number of strings in pop.

Step2. nsum, sum of all of the fitness values of the strings in pop; form nsum slots and assign string to the slots according to the fitness value of the string.

Step3. Do step 4 (pop-size -1) times.

Step4. Generate a random number between 1 and nsum, and use it to index into the slots to find the corresponding string; add this string to newpop
Step5. Add the string with the highest fitness value in pop to newpop.

\section{Position Based Crossover (PBX)}

(i) Select a set of positions from one string at random,

(ii) Produce a new string by copying the symbols on these positions into the corresponding positions in the new string,

(iii) Delete the symbols already selected from the second string. The resulting sequence contains only the symbols that the new string needs,

(iv) Place the symbols into unfixed positions in the new string from left to right according to the order of the sequence used to produce one offspring.

\section{Inversion Mutation}

It can be seen from Fig. 3. that the inversion mutation selects two positions at random and then swaps the genes on these positions. 


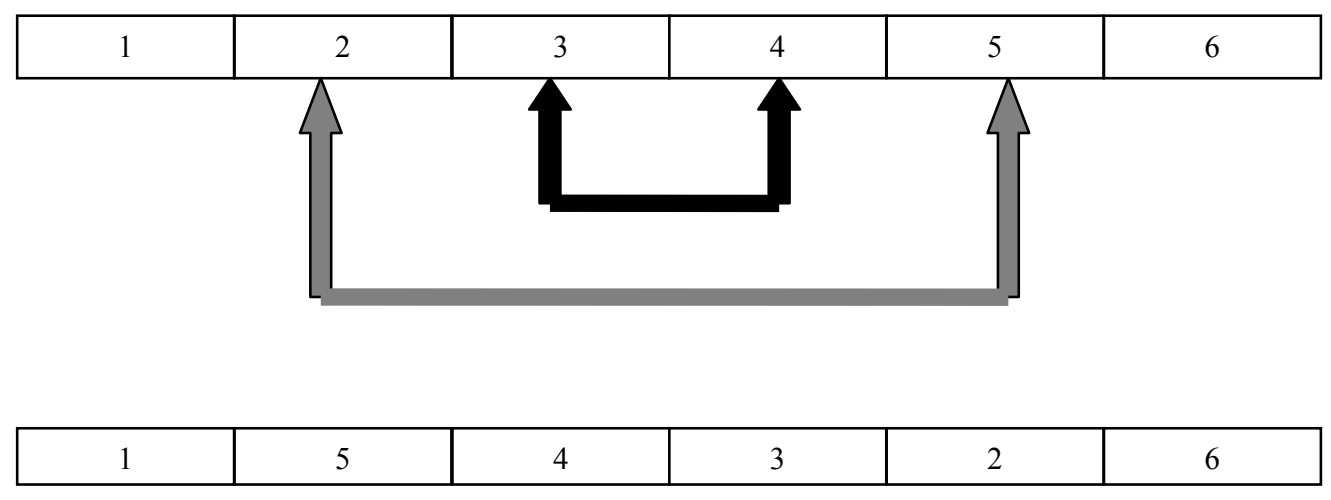

Figure 3. The Inversion mutation operators

\subsection{Computational study}

The test problems used in the experiments are Carlier and Neron's (2000) benchmark problems. The same problems were also studied by Santos et al. (1995) Engin and Döyen (2004) and Alaykiran et al. (2007). Santos et al. (1995) used a branch and bound method, Engin and Döyen (2004) used an artificial immune systems (AIS) method which was improved with the use of satisfability tests and time-bound adjustments and also Alaykiran et al. (2007) used ant colony optimization method. Santos et al. (1995), Engin and Döyen (2004) and Alaykiran et al. (2007) limited their algorithm with 1600 s. If an optimal solution was not found within 1600 s, the search was stopped and the best solution was accepted as the final schedule. They calculated the Lower Bounds $(L B)$ of the problems and the relative gap from these bounds for the nonoptimally solved instances.
In this study, using the lower bounds, the percentage deviation from LB is calculated as

$\%$ Deviation $=\frac{\text { Best } C \text { max }- \text { Lower Bound }(L B)}{\text { Lower Bound }(L B)} \times 100$

The iteration number is selected as 1000 and only one replicated for all benchmark problems. Also CPU time is limited to $1600 \mathrm{~s}$. If an optimal solution is not found within this time, the search is stopped and the best solution is accepted as the final schedule. The algorithm is implemented in Borland Delphi and run on a PC Pentium 4 processor with $3 \mathrm{GHz}$ and $512 \mathrm{MB}$ memory. In Table 4, for all of the 77 problems, the best $C_{\max }$ values and CPU times obtained by the proposed GA model, Engin and Döyen's (2004) AIS model, and Neron et al's (2001) B\&B model are presented. For all methods (GA, AIS and B\&B) the CPU times are given in seconds. The lower bounds and $\%$ deviations from lower bounds are given at the last three columns of Table 4 . 
Table 4: Solutions of Test Problems

\begin{tabular}{|c|c|c|c|c|c|c|c|c|c|c|}
\hline Problem & $\begin{array}{c}\text { GA } \\
\text { Cmax } \\
\end{array}$ & $\begin{array}{c}\mathrm{GA} \\
\mathrm{CPU}\end{array}$ & $\begin{array}{c}\text { AIS } \\
\text { Cmax } \\
\end{array}$ & $\begin{array}{l}\text { AIS } \\
\text { CPU }\end{array}$ & $\begin{array}{l}\text { B \& B } \\
\text { Cmax }\end{array}$ & $\begin{array}{l}\text { B \& B } \\
\text { CPU }\end{array}$ & $\begin{array}{l}\text { LB of } \\
\text { Cmax }\end{array}$ & $\begin{array}{c}\text { GA \% } \\
\text { deviation }\end{array}$ & $\begin{array}{cc}\text { AIS } \\
\% \text { deviation } \\
\end{array}$ & $\begin{array}{c}\mathrm{B} \& \mathrm{~B} \\
\% \text { deviation }\end{array}$ \\
\hline $\mathrm{j} 10 \mathrm{c} 5 \mathrm{a} 2$ & 88 & 0.000 & 88 & 1 & 88 & 13 & 88 & 0 & 0 & 0 \\
\hline $\mathrm{j} 10 \mathrm{c} 5 \mathrm{a} 3$ & 117 & 0.000 & 117 & 1 & 117 & 7 & 117 & 0 & 0 & 0 \\
\hline $\mathrm{j} 10 \mathrm{c} 5 \mathrm{a} 4$ & 121 & 0.015 & 121 & 1 & 121 & 6 & 121 & 0 & 0 & 0 \\
\hline $\mathrm{j} 10 \mathrm{c} 5 \mathrm{a} 5$ & 122 & 0.000 & 122 & 1 & 122 & 11 & 122 & 0 & 0 & 0 \\
\hline $\mathrm{j} 10 \mathrm{c} 5 \mathrm{a} 6$ & 110 & 0.015 & 110 & 4 & 110 & 6 & 110 & 0 & 0 & 0 \\
\hline $\mathrm{j} 10 \mathrm{c} 5 \mathrm{~b} 1$ & 130 & 0.000 & 130 & 1 & 130 & 13 & 130 & 0 & 0 & 0 \\
\hline $\mathrm{j} 10 \mathrm{c} 5 \mathrm{~b} 2$ & 107 & 0.000 & 107 & 1 & 107 & 6 & 107 & 0 & 0 & 0 \\
\hline $\mathrm{j} 10 \mathrm{c} 5 \mathrm{~b} 3$ & 109 & 0.000 & 109 & 1 & 109 & 9 & 109 & 0 & 0 & 0 \\
\hline $\mathrm{j} 10 \mathrm{c} 5 \mathrm{~b} 4$ & 122 & 0.000 & 122 & 2 & 122 & 6 & 122 & 0 & 0 & 0 \\
\hline $\mathrm{j} 10 \mathrm{c} 5 \mathrm{~b} 5$ & 153 & 0.000 & 153 & 1 & 153 & 6 & 153 & 0 & 0 & 0 \\
\hline j10c5b6 & 115 & 0.000 & 115 & 1 & 115 & 11 & 115 & 0 & 0 & 0 \\
\hline $\mathrm{j} 10 \mathrm{c} 5 \mathrm{c} 1$ & 68 & 0.031 & 68 & 32 & 68 & 28 & 68 & 0 & 0 & 0 \\
\hline $\mathrm{j} 10 \mathrm{c} 5 \mathrm{c} 2$ & 74 & 0.016 & 74 & 4 & 74 & 19 & 74 & 0 & 0 & 0 \\
\hline j10c5c3 & 71 & 0.016 & 72 & $\mathbf{a}$ & 71 & 240 & 71 & 0 & 1.4 & 0 \\
\hline $\mathrm{j} 10 \mathrm{c} 5 \mathrm{c} 4$ & 66 & 0.031 & 66 & 3 & 66 & 1017 & 66 & 0 & 0 & 0 \\
\hline $\mathrm{j} 10 \mathrm{c} 5 \mathrm{c} 5$ & 78 & 0.094 & 78 & 14 & 78 & 42 & 78 & 0 & 0 & 0 \\
\hline $\mathrm{j} 10 \mathrm{c} 5 \mathrm{c} 6$ & 69 & 0.000 & 69 & 12 & 69 & $4865 b$ & 69 & 0 & 0 & 0 \\
\hline $\mathrm{j} 10 \mathrm{c} 5 \mathrm{~d} 1$ & 66 & 0.046 & 66 & 5 & 66 & $6490 \mathrm{~b}$ & 66 & 0 & 0 & 0 \\
\hline $\mathrm{j} 10 \mathrm{c} 5 \mathrm{~d} 2$ & 73 & 0.110 & 73 & 31 & 73 & $2617 \mathrm{~b}$ & 73 & 0 & 0 & 0 \\
\hline $\mathrm{j} 10 \mathrm{c} 5 \mathrm{~d} 3$ & 64 & 0.015 & 64 & 15 & 64 & 481 & 64 & 0 & 0 & 0 \\
\hline $\mathrm{j} 10 \mathrm{c} 5 \mathrm{~d} 4$ & 70 & 0.000 & 70 & 5 & 70 & 393 & 70 & 0 & 0 & 0 \\
\hline $\mathrm{j} 10 \mathrm{c} 5 \mathrm{~d} 5$ & 66 & 0.031 & 66 & 1446 & 66 & $1627 \mathrm{~b}$ & 66 & 0 & 0 & 0 \\
\hline $\mathrm{j} 10 \mathrm{c} 5 \mathrm{~d} 6$ & 62 & 0.062 & 62 & 8 & 62 & $6861 b$ & 62 & 0 & 0 & 0 \\
\hline j10c10a1 & 139 & 0.015 & 139 & 1 & 139 & 41 & 139 & 0 & 0 & 0 \\
\hline $\mathrm{j} 10 \mathrm{c} 10 \mathrm{a} 2$ & 158 & 0.125 & 158 & 18 & 158 & 21 & 158 & 0 & 0 & 0 \\
\hline j10c10a3 & 148 & 0.047 & 148 & 1 & 148 & 58 & 148 & 0 & 0 & 0 \\
\hline j10c10a4 & 149 & 0.141 & 149 & 2 & 149 & 21 & 149 & 0 & 0 & 0 \\
\hline $\mathrm{j} 10 \mathrm{c} 10 \mathrm{a} 5$ & 148 & 0.000 & 148 & 1 & 148 & 36 & 148 & 0 & 0 & 0 \\
\hline j10c10a6 & 146 & 0.156 & 146 & 4 & 146 & 20 & 146 & 0 & 0 & 0 \\
\hline j10c10b1 & 163 & 0.000 & 163 & 1 & 163 & 36 & 163 & 0 & 0 & 0 \\
\hline $\mathrm{j} 10 \mathrm{c} 10 \mathrm{~b} 2$ & 157 & 0.131 & 157 & 1 & 157 & 66 & 157 & 0 & 0 & 0 \\
\hline j10c10b3 & 169 & 0.000 & 169 & 1 & 169 & 19 & 169 & 0 & 0 & 0 \\
\hline j10c10b4 & 159 & 0.015 & 159 & 1 & 159 & 20 & 159 & 0 & 0 & 0 \\
\hline j10c10b5 & 165 & 0.016 & 165 & 1 & 165 & 33 & 165 & 0 & 0 & 0 \\
\hline j10c10b6 & 165 & 0.016 & 165 & 1 & 165 & 34 & 165 & 0 & 0 & 0 \\
\hline j10c10c1 & 115 & 0.062 & 115 & $\mathrm{a}$ & 127 & $\mathrm{c}$ & 113 & 1.8 & 1.8 & 12.4 \\
\hline j10c10c2 & 117 & 0.141 & 119 & $\mathbf{a}$ & 116 & 1100 & 116 & 0.86 & 2.6 & $\mathbf{0}$ \\
\hline $\mathrm{j} 10 \mathrm{c} 10 \mathrm{c} 3$ & 116 & 0.234 & 116 & $\mathrm{a}$ & 133 & $\mathrm{c}$ & 98 & 18.4 & 18.4 & 35.7 \\
\hline j10c10c4 & 120 & 0.281 & 120 & $\mathrm{a}$ & 135 & $\mathrm{c}$ & 103 & 16.5 & 16.5 & 31.1 \\
\hline j10c10c5 & 125 & 0.721 & 126 & $\mathbf{a}$ & 145 & c & 121 & 3.3 & 4.1 & 19.8 \\
\hline $\mathrm{j} 10 \mathrm{c} 10 \mathrm{c} 6$ & 106 & 0.046 & 106 & $\mathrm{a}$ & 112 & $\mathrm{c}$ & 97 & 9.3 & 9.3 & 15.5 \\
\hline
\end{tabular}


Table 4: Solutions of Test Problems (continued)

\begin{tabular}{|c|c|c|c|c|c|c|c|c|c|c|}
\hline Problem & $\begin{array}{l}\text { GAs } \\
\text { Cmax }\end{array}$ & $\begin{array}{l}\text { GAs } \\
\text { CPU }\end{array}$ & $\begin{array}{c}\text { AIS } \\
\text { Cmax }\end{array}$ & $\begin{array}{l}\text { AIS } \\
\text { CPU }\end{array}$ & $\begin{array}{l}\text { B \&B } \\
\text { Cmax }\end{array}$ & $\begin{array}{l}\text { B \& B } \\
\text { CPU }\end{array}$ & $\begin{array}{l}\text { LB of } \\
\text { Cmax }\end{array}$ & $\begin{array}{c}\text { GAs } \\
\% \text { deviation }\end{array}$ & $\begin{array}{cc} & \text { AIS } \\
\% & \text { deviation }\end{array}$ & $\begin{array}{c}\mathrm{B} \& \mathrm{~B} \\
\% \text { deviation }\end{array}$ \\
\hline $\mathrm{j} 15 \mathrm{c} 5 \mathrm{a} 1$ & 178 & 0.031 & 178 & 1 & 178 & 18 & 178 & 0 & 0 & 0 \\
\hline $\mathrm{j} 15 \mathrm{c} 5 \mathrm{a} 2$ & 165 & 0.015 & 165 & 1 & 165 & 35 & 165 & 0 & 0 & 0 \\
\hline $\mathrm{j} 15 \mathrm{c} 5 \mathrm{a} 3$ & 130 & 0.015 & 130 & 1 & 130 & 34 & 130 & 0 & 0 & 0 \\
\hline $\mathrm{j} 15 \mathrm{c} 5 \mathrm{a} 4$ & 156 & 0.015 & 156 & 2 & 156 & 21 & 156 & 0 & 0 & 0 \\
\hline j15c5a5 & 164 & 0.046 & 164 & 1 & 164 & 34 & 164 & 0 & 0 & 0 \\
\hline j15c5a6 & 178 & 0.032 & 178 & 1 & 178 & 38 & 178 & 0 & 0 & 0 \\
\hline $\mathrm{j} 15 \mathrm{c} 5 \mathrm{~b} 1$ & 170 & 0.015 & 170 & 1 & 170 & 16 & 170 & 0 & 0 & 0 \\
\hline $\mathrm{j} 15 \mathrm{c} 5 \mathrm{~b} 2$ & 152 & 0.015 & 152 & 1 & 152 & 25 & 152 & 0 & 0 & 0 \\
\hline $\mathrm{j} 15 \mathrm{c} 5 \mathrm{~b} 3$ & 157 & 0.015 & 157 & 1 & 157 & 15 & 157 & 0 & 0 & 0 \\
\hline $\mathrm{j} 15 \mathrm{c} 5 \mathrm{~b} 4$ & 147 & 0.015 & 147 & 1 & 147 & 37 & 147 & 0 & 0 & 0 \\
\hline $\mathrm{j} 15 \mathrm{c} 5 \mathrm{~b} 5$ & 166 & 0.016 & 166 & 2 & 166 & 20 & 166 & 0 & 0 & 0 \\
\hline $\mathrm{j} 5 \mathrm{c} 5 \mathrm{~b} 6$ & 175 & 0.015 & 175 & 1 & 175 & 23 & 175 & 0 & 0 & 0 \\
\hline $\mathrm{j} 15 \mathrm{c} 5 \mathrm{c} 1$ & 85 & 0.031 & 85 & 774 & 85 & $2131 b$ & 85 & 0 & 0 & 0 \\
\hline $\mathrm{j} 15 \mathrm{c} 5 \mathrm{c} 2$ & 91 & 0.156 & 91 & $\mathrm{a}$ & 90 & 184 & 90 & 1.1 & 1.1 & 0 \\
\hline $\mathrm{j} 15 \mathrm{c} 5 \mathrm{c} 3$ & 87 & 0.109 & 87 & 16 & 87 & 202 & 87 & 0 & 0 & 0 \\
\hline $\mathrm{j} 15 \mathrm{c} 5 \mathrm{c} 4$ & 89 & 0.000 & 89 & 317 & 90 & $\mathrm{c}$ & 89 & 0 & 0 & 1.1 \\
\hline j15c5c5 & 75 & $\mathbf{A}$ & 74 & $\mathbf{a}$ & 84 & c & 73 & 2.27 & 1.4 & 15.1 \\
\hline $\mathrm{j} 15 \mathrm{c} 5 \mathrm{c} 6$ & 91 & 0.047 & 91 & 19 & 91 & 57 & 91 & 0 & 0 & 0 \\
\hline $\mathrm{j} 15 \mathrm{c} 5 \mathrm{~d} 1$ & 167 & 0.015 & 167 & 1 & 167 & 24 & 167 & 0 & 0 & 0 \\
\hline $\mathrm{j} 15 \mathrm{c} 5 \mathrm{~d} 2$ & 84 & 0.406 & 84 & $\mathrm{a}$ & 85 & $\mathrm{c}$ & 82 & 2.4 & 2.4 & 3.7 \\
\hline $\mathrm{j} 15 \mathrm{c} 5 \mathrm{~d} 3$ & 83 & 0.015 & 83 & $\mathrm{a}$ & 96 & $\mathrm{c}$ & 77 & 7.8 & 7.8 & 24.7 \\
\hline $\mathrm{j} 15 \mathrm{c} 5 \mathrm{~d} 4$ & 84 & 0.188 & 84 & $\mathrm{a}$ & 101 & $\mathrm{c}$ & 61 & 37.7 & 37.7 & 65.6 \\
\hline $\mathrm{j} 15 \mathrm{c} 5 \mathrm{~d} 5$ & 80 & 0.105 & 80 & $\mathrm{a}$ & 97 & $\mathrm{c}$ & 67 & 19.4 & 19.4 & 44.8 \\
\hline j15c5d6 & 82 & 0.406 & 82 & a & 87 & c & 79 & 2.53 & 3.8 & 10.1 \\
\hline j15c10a1 & 236 & 0.015 & 236 & 1 & 236 & 40 & 236 & 0 & 0 & 0 \\
\hline $\mathrm{j} 15 \mathrm{c} 10 \mathrm{a} 2$ & 200 & 0.015 & 200 & 30 & 200 & 154 & 200 & 0 & 0 & 0 \\
\hline j15c10a3 & 198 & 0.063 & 198 & 4 & 198 & 45 & 198 & 0 & 0 & 0 \\
\hline $\mathrm{j} 15 \mathrm{c} 10 \mathrm{a} 4$ & 225 & 0.031 & 225 & 12 & 225 & 78 & 225 & 0 & 0 & 0 \\
\hline j15c10a5 & 182 & 0.016 & 182 & 2 & 183 & $\mathrm{c}$ & 182 & 0 & 0 & 0.5 \\
\hline j15c10a6 & 200 & 0.031 & 200 & 2 & 200 & 44 & 200 & 0 & 0 & 0 \\
\hline j15c10a1 & 222 & 0.031 & 222 & 3 & 222 & 70 & 222 & 0 & 0 & 0 \\
\hline $\mathrm{j} 15 \mathrm{c} 10 \mathrm{~b} 2$ & 187 & 0.047 & 187 & 1 & 187 & 80 & 187 & 0 & 0 & 0 \\
\hline $\mathrm{j} 15 \mathrm{c} 10 \mathrm{~b} 3$ & 222 & 0.015 & 222 & 1 & 222 & 80 & 222 & 0 & 0 & 0 \\
\hline j15c10b4 & 221 & 0.016 & 221 & 1 & 221 & 84 & 221 & 0 & 0 & 0 \\
\hline $\mathrm{j} 15 \mathrm{c} 10 \mathrm{~b} 5$ & 200 & 0.094 & 200 & 1 & 200 & 84 & 200 & 0 & 0 & 0 \\
\hline j15c10b6 & 219 & 0.031 & 219 & 1 & 219 & 67 & 219 & 0 & 0 & 0 \\
\hline
\end{tabular}

a: GAs and AIS could not reach LB value in $1600 \mathrm{~s}$, b: B\&B reaches LB value more than $1600 \mathrm{~s}, \mathrm{c}$ : B\&B could not reach LB value, $\mathrm{B} \& \mathrm{~B}$ CPU

As it will be noticed from Table 4, better results for $a$ and $b$ type problems than $c$ and $d$ type problems have been obtained. The machine configurations have an important effect on the complexity of problems that effects the solution quality. GA algorithm has found the optimal 
solutions for all $a$ and $b$ type problems like AIS algorithm (47 problems), although B\&B has found the optimal solutions for 46 problems. $c$ and $d$ type problems are relatively hard problems. Neron et al. (2001) grouped some of the problems as hard problems. For these problems, they could not reach the optimal solutions in a short time. The difference of these problems is mainly sourced from their machine configurations (all of these problems are $c$ or $d$ type problems). There are 30 problems in that group (the $c$ and $d$ types of $10 \times 5$ and $15 \times 5$ problems). The rest of the problems (all $a, b$ types and $10 \times 10 c$ type problems) are referred as easy problems.

For hard problems, the proposed GA algorithm found LB values for 18 of the 24 problems while
AIS found LB values for 17 of the 24 problems. Also for these hard problems GA found a better makespan value than AIS and B\&B methods. For only two problems, GA could not reach the AIS's makespan value. These problems are represented in bold in Table 4.

The average \% deviation from LB for GA is smaller than AIS and B\&B methods'. There are 53 easy problems. Both of these methods, AIS and $B \& B$, could not reach LB values for 6 of the problems. But the average \% deviation from LB for GA algorithm is smaller than AIS and B\&B methods'. In Table 5, the percentage of the solved problems and the average \% deviation values for easy and hard problems are presented.

Table 5. Performances of three methods

\begin{tabular}{ccccc} 
& \multicolumn{2}{c}{ Easy problems } & \multicolumn{2}{c}{ Hard Problems } \\
\hline Method & \% Solved & \%Deviation & \% Solved & \% Deviation \\
\hline GA & 88.7 & 0.95 & 70.8 & 3.05 \\
AIS & 88.7 & 0.99 & 66.7 & 3.13 \\
B \& B & 88.7 & 2.17 & 70.8 & 6.88 \\
\hline
\end{tabular}

As it is clearly seen from Table 5, the least deviation belongs to GA. AIS is the second with a $0.08 \%$ difference. B\&B is the worst of all with almost two times larger deviation than the others.

Also the computational results are compared with the earlier study of Alaykiran et al. (2007).
The average \% deviations from LB due to the machine layout types are calculated for GA solutions and compared with the solution of Alaykıran et al.'s (2007) AS algorithm. The computational results are given in Table 6 .

Table 6 . The average \% deviation from LB due to the machine layout types

\begin{tabular}{cccccc}
\hline Layout type & & $\mathrm{a}$ & $\mathrm{b}$ & $\mathrm{c}$ & $\mathrm{d}$ \\
\hline Average percentage & $\mathrm{AS}$ & 0.27 & 0.4 & 1.93 & 11.17 \\
\cline { 2 - 6 } deviations & GA & 0.00 & 0.00 & 2.97 & 5.81 \\
\hline
\end{tabular}

As it is seen in Table 6, the proposed GA found the optimal solutions for all $a$ and $b$ type problems, although Alaykiran et al.'s (2007) AS algorithm could not find optimal solutions. Also for $d$ type problems the proposed GA found a smaller average $\%$ deviation from LB than Alaykıran et al.'s (2007) AS algorithm's. But for $c$ type problems Alaykıran et al.'s (2007) AS algorithm found a smaller average \% deviation from LB than the proposed GA.

The proposed GA can not be compared to the AIS and B\&B according to CPU times because the configuration of the computers, in which the considered problems were solved, are different from one to another. The $1600 \mathrm{CPU}$ time is used only a stopping parameters of GA.

\section{Conclusion}

In this paper, we propose an effective GA for HFS scheduling problems with the objective of minimizing makespan. The considered problem is a NP-Hard problem. Most of the studies to solve that problem are approximate methods rather than an exact method, which guarantees optimal solution. The test problems are benchmarking problems used in the literature. The percentage deviations from lower bounds are calculated. The findings are compared with another study that tested the same problems. We obtained better solutions with the proposed GA algorithm. When all problems are considered; the average deviation of the GA Algorithm is $1.50 \%$ while the average deviations 
of AIS and B\&B are $1.657 \%$ and $3.6 \%$, respectively. Also it can be seen in Table 4 that the CPU times of the GA are much smaller than AIS and B\&B. The proposed GA is a good problem solving technique for a scheduling problem and may be used for some other industrial problems.

\section{Acknowledgements}

The authors would like to thank Jacques Carlier and Emmanuel Neron for the benchmark problems, solution files and any kind of help.

\section{References}

1. R. Linn, and W. Zhang, Hybrid Flow shop scheduling: A Survey, Computers and Industrial Engineering. 37 (1999) 57-61.

2. O. Engin, and A. Döyen, A New approach to solve hybrid flow shop scheduling problems by artificial immune system, Future generation computer systems. 20 (2004) 1083-1095.

3. J. N. D. Gupta, Two-stage hybrid flowshop scheduling problem, Operational Research Society, 39 (1988) 359-364.

4. M. A. Hong Wang, A new model in designing neural network in optimization: A hybrid neural network approach to machine scheduling, (Business Administration Graduate Program, The Ohio State University, Thesis, 1998).

5. T. S. Arthanari and K.G. Ramamurthy, An extension of two machines sequencing problem, Opsearch. 8 (1971) 10-22.

6. J. A. Hoogeveen, J. K. Lenstra, and B. Vettman, Minimizing the Makespan in a multiprocessor flow shop is strongly NP-Hard, European Journal of Operational Research. 89 (1996) 172-175.

7. L. Wang, L. Zhang, and D. Zhenga, An effective hybrid genetic algorithm for flow shop scheduling with limited buffers, Computers \& Operations Research. 33 (2006) 2960-2971.

8. C. Oğuz, and M. F. Ercan, A Genetic Algorithm for Hybrid Flow-Shop Scheduling With Multiprocessor Tasks, Journal of Scheduling. 8 (2005) 323-351.

9. T. Li-Xin, W. Y. P. Source, and Z. Xuebao, Genetic descent algorithm for hybrid flow shop scheduling, Automatica Sinica. 28(4) (2002) 637-641.

10. W. Xia, P. Hao, S. Zhang, and X. Xu, Hybrid flow shop scheduling using genetic algorithm, Proceedings of the 3nd world congress on Intelligent control and Automation. (2000) 537-541.

11. J. Carlier, and E. Neron, An exact method for solving the multiprocessor flowshop, R.A.I.R.O-R.O. 34 (2000) $1-25$.

12. S. A. Brah, and J.L. Hunsucker, Branch and bound algorithm for flow shop with multiple processors, European Journal of operations Research. 51 (1991) 88-89.

13. D. L. Santos, J. L. Hunsucker, and D. E. Deal, Global lower bounds for flow shops with multiple processors, European Journal of Operational Research. 80 (1995) 112-120.

14. F. Riane, A. Artibs, and S.E. Elmaghraby, A Hybrid three stage flow shop problem: Efficient heuristics to minimize makespan, European Journal of Operational Research 109 (1998), 321-329

15. M. C. Portman, A. Vignier, D. Dardilhac, and D. Dezalay, Branch and Bound crossed with GA to solve hybrid flowshops, European Journal of Operational Research. 107 (1998) 389-400.

16. H. T. Jessen, and M. Weizhen, On-line algorithms for hybrid flow shop scheduling, International conference on computer science and informatics. (1998) 134-137.

17. O. Moursli and Y. Pochet, A branch and bound algorithm for the hybrid flow shop, International journal of production economics. 64 (2000) 113125.

18. H. Soewandi, and S.E. Elmaghraby, Sequencing three stage flexible flowshops with identical machines to minimize makespan, IIE Transactions. 33 (2001) 985-983

19. E. Neron, P. Baptiste, and J. N. D. Gupta, Solving hybrid flow shop problem using energetic reasoning and global operations, Omega The international journal of management science, 29 (2001) 501-511.

20. L. Tang, W. Liu, and J. Liu, A Neural network model and algorithm for the hybrid flow shop scheduling problem in a dynamic environment, Journal of Intelligent Manufacturing. 16 (2005) 361-370.

21. L. Yang, H.G. Yu, and X.Y. Geng, Planning and scheduling algorithm based on TOC for complex hybrid flow shop problems, Computer integrated manufacturing systems. 11(1) (2005) 97-103.

22. M. Zandieh, S. M. T. F. Ghami, and S. M. M., Husseini, An Immune algorithm approach to hybrid flow shops scheduling with sequence-dependent setup times, Applied Mathematics and Computation. 180 (2006) 111-127

23. W. Zhong, X.F. Xu, and S. Deng, Evolutionary algorithm for solving multi-objective hybrid flowshop scheduling problem, Computer Integrated Manufacturing Systems. 12(8) (2006) 1227-1234.

24. H. Allaoui and A. Artiba Scheduling two stage hybrid flow shop with availability constraints, Computers and Operations Research. 33 (2006) 1399- 1419.

25. M. Haouari, L. Hidri, and A. Gharbi 2006, Optimal Scheduling of a two stage hybrid flow shop, Math. Meth. Oper. Res. 64 (2006) 107-124.

26. K. Alaykıran, O. Engin, and A. Döyen, Using ant colony optimization to solve hybrid flow shop scheduling problems, Int. J. Adv. Manuf. Technol. (2007) Article in press.

27. P. Caricato, A. Grieco, and D. Serino, TSP- based scheduling in a batch-wise hybrid flow shop, Robotics and Computer-Integrated Manufacturing. 23 (2007) 234-241.

28. A. Janiak, E. Kozan, M. Lichtenstein and C. Oğuz Metaheuristic approaches to hybrid flow shop scheduling problem with a cost related criterion, 
International journal of production economics. 105 (2007) 407-424.

29. S. Vob, and A. Witt, Hybrid flow shop scheduling as a multi-mode multi project scheduling problem with batching requirements: A real world application, Int. J. Production Economics. 105 (2007) 445-458.

30. D. E. Goldberg, Genetic Algorithms in Search, Optimization, and Machine Learning, (Addison Wesley Publishing, The University of Alabama, 1989)

31. S. H. Yoon, J. A. Ventura, An application of genetic algorithms to lot-streaming flow shop scheduling, IEE Transactions 34 (2002) 77-787.

32. M. Gen, and R. Cheng, Genetic Algorithms \& Engineering Optimization, (John Wiley \& Sons, New York, 2000)

33. T. Yamada, and R. Nakano, A Genetic Algorithm Applicable To Large Scale Job Shop Problems, Proceedings of The Second International Conference on Parallel Problem Solving from Nature, (Elsevier Science Publishers, 1992).

34. İ. Kaya, O. Engin, A new approach to define sample size at attributes control chart in multistage process: An application in engine piston manufacturing process, Journal of Materials Processing Technology. 183 (2007) 38-48. 